\title{
Democracia como forma de vida: Cultura política e eticidade democrática em Axel Honneth
}

\author{
Democracy as Form of Life: Political Culture and Democratic Ethicity \\ in Axel Honneth
}

\author{
Rúrion Melo \\ rurion@usp.br \\ (Universidade de São Paulo, São Paulo, Brasil)
}

\begin{abstract}
Resumo: 0 presente artigo busca analisar a ideia da democracia como forma de vida com base nos trabalhos mais recentes de Axel Honneth. Na primeira seção, eu diferencio a concepção normativa de democracia social desenvolvida por Honneth, comparando-a às versões republicana e procedimental. Em seguida, analiso de que maneira a eticidade democrática poderia ser apresentada em um maior grau de complexidade, dando atenção à efetividade da liberdade em três esferas sociais centrais: relações pessoais, interações econômicas e formação política da vontade. Trata-se aqui de atentar, sobretudo, para o modo como a cultura política democrática condensa a correlação entre as diferentes esferas sociais. Eu encerro o artigo ressaltando alguns limites da reflexão proporcionada pelo autor. De um lado, fenômenos sistemáticos de violência e dominação, que colocam de fato em risco uma democracia socialmente efetiva, estão ausentes de sua formulação; de outro, não fica claro o papel das lutas sociais para a realização diferenciada da liberdade em nossa cultura política.
\end{abstract}

Palavras-chave: eticidade democrática; forma de vida; cultura política; teoria crítica da democracia.
Abstract: The article intends to analyze the idea of democracy as a form of life based on Axel Honneth's most recent works. In the first section, I differentiate the normative conception of social democracy developed by Honneth, comparing it to the republican and procedural versions. Then, I analyze how democratic ethicity could be presented in a greater degree of complexity, paying attention to the effectiveness of freedom in three central social spheres: personal relationships, economic interactions and political will formation. It is a matter of paying attention, above all, to the way in which democratic political culture condenses the correlation between different social spheres. I close the article by emphasizing some limits of the reflection provided by the author. On the one hand, systematic phenomena of violence and domination, which in fact endanger a socially effective democracy, are absent from its formulation; on the other hand, the role of social struggles for the differentiated realization of freedom in our political culture is not clear.

Keywords: democratic ethicity; form of life; political culture; critical theory of democracy.

DOI: http://dx.doi.org/10.11606/issn.2318-9800.v25i3p75-94

Há muito tempo os movimentos sociais progressistas procuram ampliar os sentidos da democracia. Atualmente, demandas de movimentos variados (antirracista, feminista, LGBTQI+) pressupõem uma ideia comum e decisiva: a democracia é uma forma de vida. Embora nem sempre adequadamente compreendida, essa ideia acompanha pautas que remetem a experiências cotidianas generalizadas de desrespeito e violência, as quais compõem as formas de dominação estrutural da sociedade e 
colocam em risco o projeto de uma sociedade efetivamente democrática. Isso significa reconhecer que racismo, sexismo e homofobia moldam de maneira constitutiva práticas e comportamentos em diferentes dimensões da vida social, abrangendo espaços de convivência diferentes (casa, trabalho, escolas, universidades, bares, shoppings, praças, para citar apenas alguns) e produzindo injustiças em dimensões interseccionadas da política, da economia e da cultura. Portanto, na perspectiva desses movimentos, o projeto de uma vida verdadeiramente democrática precisa passar por uma luta contra tais formas de dominação estrutural: com o "Eu também", as mulheres denunciaram experiências recorrentes, mas socialmente emudecidas, de assédio e violência sexual; o "Vidas negras importam” chama atenção para o genocídio sofrido pela população afrodescendente que é vítima de profundo racismo; o "Meu corpo, minhas cores" expõe a perseguição preconceituosa e agressiva contra a população LGBTQl+. Para tais movimentos, nossa democracia, criticada por não cumprir o que promete, é problemática porque convive e, por vezes, até corrobora tais fenômenos recorrentes de violência e dominação: a democracia é uma forma de vida ameaçada.

Não há dúvidas de que a expectativa de superação prática desses fenômenos de violência vem acompanhada da aspiração normativa por uma vida democraticamente digna. Para uma teoria crítica da democracia preocupada em compreender os potenciais emancipatórios socialmente existentes, isso deve ser entendido em dois sentidos. Em primeiro lugar, se a qualidade da democracia não se mede simplesmente pelos critérios formais e arranjos institucionais de um regime político, é preciso atentar então justamente para as experiências, comportamentos e práticas que constituem os contextos cotidianos da vida social. Sobretudo neles se sedimentam as culturas políticas que sustentam, mesmo que de maneira ambígua, nossas democracias. Em segundo lugar, a aspiração por uma sociedade diferente, porque efetivamente democrática, requer assim muito mais do que transformações formais nas instituições políticas, mas sim a democratização das relações de vida nas mais diversas esferas sociais, isto é, uma profunda mudança de atitude nas interações cotidianas por parte dos membros da sociedade. As formas de vida passam a ser, portanto, um dos temas mais importantes de uma teoria crítica da democracia.

Ora, essa maneira ampliada de pensar a democracia junto ao conceito de "forma de vida" não passou despercebida de algumas formulações mais recentes da teoria crítica. ${ }^{1}$ Eu gostaria aqui de investigar essa questão a partir da teoria proposta por Axel Honneth em alguns de seus trabalhos. ${ }^{2}$ Meu intuito consiste em examinar a

1 Para uma abordagem recente, cf. em especial Jaeggi (2014).

2 Tratei da relação entre democracia, cultura política e formas de vida em outros contextos. Cf. Melo, 2017a, 2017b. Sobre o tema da "forma de vida" em Honneth, sigo algumas intuições presentes em Pinsdorf (2016). É importante ressaltar aqui que tive contato com o mais recente livro de Honneth (Die Armut unserer Freiheit, 2020) somente quando o presente artigo já estava terminado. No 
formulação honnethiana a respeito da eticidade democrática perguntando-me até que ponto ela seria frutífera para os desafios mencionados anteriormente. Em grande medida, minha resposta a esta questão será positiva. Pois há, no empreendimento de Honneth, uma tentativa de fazer com que a reflexão sobre a política, embora elaborada em um plano filosófico mais abstrato, seja reacoplada à complexidade das práticas sociais existentes. Considero que essa tentativa é frutífera para os propósitos de uma teoria crítica da democracia preocupada tanto com as experiências cotidianas de indivíduos e grupos subordinados quanto com as lutas sociais que podem moldar as transformações em nossa cultura política. Segundo o autor, os vestígios das efetivas liberdades democráticas devem ser investigados nas "mudanças do comportamento moral cotidiano" (Honneth, 2011, p.614). Seu empreendimento pretensioso o leva assim a uma ampla reconstrução da "liberdade social", ou seja, da "liberdade já efetivada de maneira rudimentar nas esferas sociais" (idem, ibidem) - "de modo rudimentar", pois as liberdades só se efetivam mediante a institucionalização da experiência social do reconhecimento recíproco, envolvendo ainda uma luta igualmente cotidiana contra sua persistente violação. Acredito que esse movimento em direção ao "social" e, principalmente, às ambiguidades da realização de liberdades recíprocas poderia ser aproveitado por uma teoria crítica preocupada com as formas de vida democráticas.

A primeira seção do artigo se dedica a diferenciar a concepção normativa de democracia de Honneth, comparando-a às versões republicana e procedimental. $\mathrm{Na}$ formulação de seu modelo já é possível perceber a disposição por ampliar o escopo da teoria democrática para dimensões mais abrangentes das interações sociais e das liberdades comunicativas (I). Em seguida, analiso de que maneira a eticidade democrática poderia ser apresentada em um maior grau de complexidade, dando atenção à efetividade da liberdade em três esferas sociais centrais: relações pessoais, interações econômicas e formação política da vontade. A qualidade da democracia, segundo essa exposição, dependerá do grau de efetivação da liberdade social nessas diferentes esferas da vida que compõem a eticidade moderna. Tratase aqui de atentar, sobretudo, para o modo como a cultura política democrática condensa a "correlação" [Zusammenspiel] entre as diferentes esferas sociais, ou seja, resulta da efetivação, sempre dinâmica, da liberdade individual nas relações cotidianas de esfera sociais diferenciadas. A democracia provém assim das formas de vida que, mediante suas práticas, hábitos e instituições sociais, simultaneamente possibilitam e ameaçam a liberdade de cada um de nós. E é deste ponto de vista "social" que a crítica precisa ser fundamentada (II). Contudo, embora Honneth

entanto, fica evidente nos textos que compõem o referido volume que Honneth mantém o enfoque nas relações sociais para investigar criticamente os potenciais democráticos de nossas sociedades modernas. Cf., sobretudo, a seção dedicada às "deformações da liberdade social". 
permita à teoria crítica compreender como o ideal democrático está sustentado por comportamentos e disposições sociais, eu encerro o artigo ressaltando alguns limites da reflexão proporcionada pelo autor. De um lado, fenômenos sistemáticos de violência e dominação, que colocariam em risco uma democracia socialmente efetiva, estão ausentes de sua "reconstrução normativa"; de outro, não fica claro o papel das "lutas sociais" para a realização da liberdade na correlação das esferas sociais e, por conseguinte, da cultura política (III).

No debate filosófico atual em torno de temas centrais sobre moral e justiça, Honneth sempre reforçou a importância da abordagem hegeliana diante de outras vertentes teóricas, em especial as liberais. No entanto, embora Honneth tenha criticado diversas vezes a corrente liberal-kantiana, não é possível qualificar sua posição simplesmente como republicana ou mesmo comunitarista. ${ }^{3}$ Não pretendo entrar nesta complicada questão aqui. Para meus propósitos, acredito ser suficiente admitir que a contribuição hegeliana de Honneth é peculiar pelo fato de sua teoria privilegiar a dimensão do "social". O olhar diferenciado de sua reconstrução do social consiste em mostrar como os princípios normativos das sociedades modernas são engendrados, em diferentes esferas da eticidade, pelas práticas e costumes que subjazem às nossas instituições sociais e políticas. ${ }^{4}$

Apesar de tema crucial para o desenvolvimento de sua teoria crítica, Honneth levou muitos anos para tratar explicitamente das teorias contemporâneas da democracia. E quando o fez, ao defender um modelo de democracia elaborado com base na teoria de John Dewey, aquela preocupação com a dimensão do "social" saltou uma vez mais ao primeiro plano. Pois, de acordo com Honneth, o alcance mais "radical" de um almejado modelo crítico não poderia se limitar a pensar o ideal normativo de democracia unicamente como um ideal político, "mas, sobretudo, como um ideal social” (Honneth, 2000, p. 309). ${ }^{5}$ Logo, é em virtude da reconstrução de um modelo social de democracia que o autor confronta outras versões radicais

3 Sobre o debate entre liberais e comunitaristas, cf. Forst (2010), Wellmer (1993). Para a crítica de Honneth ao mesmo debate, cf. Honneth (2007, p. 45-53).

4 Essa formulação específica se enquadra no projeto da "reconstrução normativa" apresentada, sobretudo, em $O$ direito da liberdade. No entanto, a importância do "social" abarca suas obras anteriores. Cf. Honneth (1986, 2000a, 2003). Sobre essa questão no modelo crítico de Honneth, cf. Nobre (2013).

5 Em relação ao debate sobre os modelos normativos de democracia, a referência mais importante encontra-se em Habermas $(2018,2020)$. Como veremos, Honneth considera limitada a abordagem habermasiana das concepções de democracia, cuja normatividade acaba sendo derivada de ideais abstratos, muito descolados da dimensão social em que a reconstrução de tais modelos deveria se fundamentar. Este argumento sobre a teoria democrática pode ser compreendido como desdobramento da crítica mais geral levantada contra a teoria habermasiana, que padeceria de um "déficit sociológico". Sobre este ponto, cf. Honneth (1986). 
de teorias democráticas, a saber, a republicana e a procedimental, alegando que em ambas seria possível atribuir um "papel maior à formação democrática da vontade do que em geral ocorre no liberalismo político" (Honneth, 2000b, p. 283). ${ }^{6}$ Ambas as concepções deslocam a questão acerca da legitimidade democrática dos mecanismos eleitorais de representação para a participação dos cidadãos na esfera pública e para os processos de formação política da opinião e da vontade. No entanto, em cada caso, o princípio democrático é normativamente justificado de forma diferente.

De acordo com a interpretação de Honneth, o republicanismo atribui primazia ao autogoverno de uma comunidade política e à negociação pública e ativa dos cidadãos. Dois pressupostos substantivos fortes operam na justificação de seus princípios democráticos. Em primeiro lugar, a política seria parte essencial da vida dos cidadãos. A atividade política não se esgota na persecução de interesses individuais e isolados, mas antes de tudo na busca por um bem comum. Em segundo lugar, essa forma reflexiva da atividade conjunta da política é motivada pela "virtude cívica" de cada cidadão, que reconhece o valor superior do exercício da cidadania na medida em que estimam se tornar sujeitos políticos responsáveis de uma comunidade de livres e iguais. 0 ideal democrático só pode ser implementado, portanto, pelo exercício da autodeterminação pública, pela práxis comum da liberdade política. 0 modelo procedimental, por sua vez, também valoriza a autonomia política, contudo sem precisar contar com virtudes cívicas arraigadas ou a força constitutiva do bem. Pois a justificação normativa da democracia estaria apoiada unicamente nos procedimentos racionais de formação pública da opinião e da vontade. O próprio Honneth reconhece em Jürgen Habermas o mais importante representante da concepção procedimental. Sabe-se que a teoria habermasiana da democracia depende antes das condições de comunicação e dos procedimentos que dariam à formação da opinião e da vontade, já juridicamente institucionalizada, sua força legitimadora: são as condições comunicativas que sustentam a ideia de que o processo político, deliberativamente realizado, teria a seu favor a suposição de produzir resultados racionais (Habermas, 2020).

Outra característica importante nos dois modelos diz respeito à relação da esfera pública com o Estado democrático de direito. É certo que, em termos ainda normativos, o republicanismo não parece dar tanta centralidade à relação com as instituições legais do Estado quanto o modelo procedimental de democracia. Em todo caso, o Estado de direito é avaliado quanto à sua legitimidade democrática na medida em que é capaz de implementar os acordos publicamente negociados

\footnotetext{
6 Não poderei analisar criticamente nos limites deste artigo os problemas da reconstrução que Honneth oferece desses dois modelos típico-ideais de democracia, embora eu reconheça que tais generalizações sempre correm o risco de inconsistência conceitual, não fazendo jus aos autores e às correntes pressupostos. Por esta razão, eu me restrinjo nesta seção a somente reproduzir as pretensões levantadas pelo próprio Honneth diante dos outros modelos de democracia.
} 
da comunidade política: normas legais, afirma Honneth, são concebidas como “instrumento social pela qual a comunidade política protege sua própria identidade" (Honneth, 2000b, p. 284). A concepção procedimental, por sua vez, reforça que a legitimidade política do direito não surge apenas como projeção direta da autocompreensão da comunidade política, mas sim por causa dos procedimentos, juridicamente assegurados, de formação pré-parlamentar da opinião pública que antecedem as decisões institucionalizadas. Em ambos os casos, a análise sobre o papel central da esfera pública política está conectada com as funções e garantias jurídico-políticas do Estado de direito. Principalmente o modelo procedimental sustenta que a autonomia cidadã seja compreendida com base na garantia legal previamente assegurada por instituições jurídicas. Cabe ressaltar, no entanto, que o intuito maior dos dois modelos é mostrar que o Estado de direito deve respeitar os princípios radicalmente democráticos de suas concepções, ou seja, que as instituições formais do Estado poderiam ser democraticamente transformadas ou corrigidas.

Honneth defenderá, diante de tais concepções normativas de democracia, um terceiro modelo, que será inspirado na teoria de Dewey (1954). Como dissemos, se a Honneth interessa manter dessas duas concepções o cerne radical da formação democrática da opinião e da vontade, em sua visão elas ainda limitam a abrangência social das possibilidades de autonomia. Isso ocorreria por duas razões: de um lado, seus pressupostos normativos não permitiriam abarcar fenômenos multifacetados da eticidade, e, de outro, ambas restringiriam a práxis política à dimensão pública de autodeterminação. 0 pressuposto excessivamente substantivo do republicanismo se apoia sobre uma concepção homogênea e totalizante de bem comum, ignorando a relação da autocompreensão ética da comunidade política com as formas diversas de individuação, os modos de vida plurais dos indivíduos, e a diversidade funcional de esferas de ação. Já o procedimentalismo pretende esvaziar de seu princípio normativo conteúdos ético-políticos previamente dados, de modo que a justificação dos ideais democráticos fique circunscrita à construção de processos sempre públicos de formação da opinião e da vontade constituídos de maneira racional.

A alternativa aberta pela retomada da teoria democrática de Dewey consiste em entrelaçar simultaneamente procedimentos racionais e autocompreensão da comunidade política, conectando-os a um tipo de justificação dos princípios de uma "democracia ampliada" (Honneth, 2000b, p. 286) que também inclua em sua fundamentação formas reflexivas de cooperação social em diferentes esferas da eticidade. ${ }^{7}$ Haveria assim uma preocupação política abrangente na

7 Essa alternativa decorre antes de tudo da tradição pragmática de Dewey, sobre a qual Honneth passará a desenvolver (apoiando-se também em outros teóricos sociais, tais como $\mathrm{E}$. Durkheim e T. Parsons) uma ideia sistemática de diferenciação funcional das esferas de ação que em seu conjunto formam a sociedade moderna. Honneth chegará a defender um "funcionalismo normativo" (Honneth, 2011). Muitas críticas foram feitas a essa incorporação crescente do funcionalismo em sua 
formulação de Dewey que a permite, na visão honnethiana, representar uma opção superior de teoria radicalmente democrática. A ideia da "democracia como cooperação reflexiva" pressupõe que uma sociedade democrática deve permitir que seus princípios normativos ("liberdade, igualdade e fraternidade") perpassem esferas amplas da vida social, incluindo formas de interação cotidiana, hábitos e comportamentos que compõem uma “dimensão pré-política de comunicação social” (idem, p. 294). Precisamente essa dimensão teria sido de certo modo negligenciada pelo republicanismo e pela teoria procedimental da democracia. Porém, somente a partir dela poderíamos produzir "um conceito mais forte, mais exigente de formação democrática da vontade" (idem, p. 305).

O ideal da autonomia democrática de cada cidadão precisa ser aplicado à visão mais abrangente segundo a qual toda democracia deveria necessariamente emergir das condições intersubjetivas da vida social. De acordo com Honneth, ao pressupor a "incorporação da soberania popular em cada cidadão individual” (Honneth, 2000b, p. 291), Dewey traz para o chão das interações que formam a vida ética os ideais democráticos da igual liberdade de cada indivíduo. "Uma constituição democrática", afirma Honneth,

pressupõe liberdade individual no sentido de um desenvolvimento natural da personalidade, que, sob condições de igualdade institucionalizada de oportunidades, permite a cada membro da sociedade desenvolver as capacidades e potencialidades necessárias para, em associação com todas as outras pessoas, perseguir de forma fraterna, ou melhor, solidária, fins compartilhados (idem, p. 293-294).

Por conseguinte, se as formas cooperativas de liberdade comunicativa e de autorrealização individual forem violadas, se não for possível garantir a todos os integrantes da sociedade que a interação e a comunicação se manterão livres de dominação, então os próprios ideais democráticos também estarão sob o risco de ser violados e perder efetividade social. O que torna mais complexa a questão em termos políticos é que as "garantias" mencionadas não devem se limitar às constrições legais do direito positivo, mas sim à observância cotidiana desses princípios promovida por processos instáveis de aprendizagem social, cuja estabilidade remete antes de tudo à cultura política de fundo. ${ }^{9}$

teoria. Para uma análise crítica da tendência funcionalista nas últimas obras, cf. Teixeira (2016), Deranty (2018). Retomarei esse ponto na última seção.

8 "Liberdade para ele é principalmente a experiência positiva de uma autorrealização natural que ensina ao indivíduo como descobrir seus talentos e suas capacidades por meio dos quais ele pode, por fim, contribuir com a preservação, em termos de divisão do trabalho, do todo social" (Honneth, 2000b, p. 293).

9 Questão que remete à investigação semelhante feita em outro contexto: "Mesmo se contássemos com instituições legalmente estáveis e bem avaliadas do ponto de vista da democracia política, não seria possível afirmar que vivemos de fato em uma sociedade democrática se continuamos convivendo com experiências sociais de racismo, sexismo, ou outros tipos de violação social da autonomia. Ter autonomia significa não se submeter à dominação e à violência nos diversos contextos sociais da 
Encontramos nessa preocupação com as interações sociais que sustentam os ideais e princípios da democracia a diferença a ser destacada em relação aos modelos apresentados. Honneth critica Habermas por ter se limitado exclusivamente ao estabelecimento de procedimentos democráticos para avaliar a legitimidade de processos políticos. Mas somente os procedimentos racionais de deliberação institucionalizada não nos aproximam das instâncias em que as expectativas de reconhecimento recíproco e a liberdade individual tornam-se efetivas mediante práticas e comportamentos nas interações cooperativas. A disposição individual a cooperar solidariamente em diferentes contextos de interação - não apenas as condições comunicativas da aceitabilidade racional de princípios e normas - sustenta significativamente o projeto mais amplo de uma sociedade democrática. Com Dewey, seria possível recuar para as experiências éticas relativas à motivação individual de cada cidadão em participar cooperativamente tanto de interações sociais "prépolíticas" quanto dos processos políticos na esfera pública: "para que os cidadãos reúnam finalmente motivos e interesses para participar da formação pública da opinião e da vontade, eles têm de ter feito dos procedimentos democráticos um elemento normativo de seus hábitos cotidianos" (Honneth, 2000b, p. 308). Se os pressupostos mais substantivos dessa concepção podem preencher a lacuna motivacional de um "procedimentalismo vazio", o modelo social de democracia apresentado por Honneth também difere de um "republicanismo demasiadamente ético". Ainda que atento à superação do "déficit motivacional” do procedimentalismo, seu modelo pretende ser mais adequado do que o republicanismo ao ethos democrático de sociedades modernas e plurais.

Portanto, segundo a formulação de Honneth, a legitimidade democrática depende em grande medida da efetividade social da liberdade comunicativa. Procedimentos democráticos, como aqueles que podemos reconhecer na formação política da opinião e da vontade, são geneticamente engendrados pelas práticas sociais cotidianas, por "posturas sobrepostas de expectativa" que são formadas em longo prazo por “hábitos de ação socialmente úteis” (Honneth, 2000b, p. 296297). Em outros termos, a gênese da democracia está localizada nas experiências de reconhecimento recíproco em que os integrantes de uma sociedade cooperam reflexivamente. Desse modo, interações sociais cotidianas, que materializam a comunicação livre de coerção, precisam ser incluídas no que Honneth propõe como modelo radical de democracia e não podem escapar à questão da legitimidade. Assim, a pergunta pela democratização das instituições formais do Estado de direito começa a ser deslocada para aquela acerca da democratização das próprias formas de vida.

vida [...]. Implica, portanto, poder se autogovernar (ou seja, a capacidade de se autorrealizar e se autodeterminar) no cotidiano de suas interações sociais" (Melo, 2017a, p. 66). 
Essa concepção social normativamente apresentada de democracia traz contribuições importantes para a teoria democrática. O que entendemos por "comunidade política" modifica-se sensivelmente, passando a abranger interações ocorridas em esferas variadas de ação. Isso significa, antes de tudo, não restringir a democracia apenas a uma forma política de governo. E, além disso, de maneira complementar, implica pensar a eticidade moderna como constituída por dimensões sociais que são internamente estruturadas de maneira democrático-associativa. Não apenas em relação à deliberação política na esfera pública, mas também no que diz respeito a outras dimensões sociais (a esfera privada e a dimensão das relações econômicas, como veremos) Honneth procura reconstruir os vestígios da liberdade social e compreender sua importância para a constituição da ideia de uma democracia como forma de vida. Para tanto, é necessário entender a institucionalização mais complexa de práticas sociais nas quais a realização da liberdade individual de uma pessoa deveria estar vinculada ao reconhecimento e à possibilidade da liberdade das outras. Pois apenas pela livre complementação de cada um em suas atitudes e modos de ação uma comunidade de indivíduos, ao consumar condições sociais para a efetivação de sua liberdade, seria qualificada de democrática.

Para acompanharmos a constituição da liberdade em diferentes esferas de ação, temos de saber quais são então as práticas sociais centrais que as formam. Ora, o amplo tecido social da "eticidade democrática" é precisamente o que Honneth procura reconstruir normativamente no seu livro $O$ direito da liberdade. É possível compreender um dos propósitos do livro como a exposição de uma "teoria da democracia como análise da sociedade", ${ }^{10}$ voltada às práticas e instituições nas quais a liberdade é socialmente exercida. 0 outro propósito geral do livro é mostrar que, a despeito da institucionalização da liberdade nas esferas sociais que compõem a sociedade moderna, sua efetivação não se realizou plenamente. Por isso a necessidade crítica de dar atenção às patologias e anomalias que assolam a liberdade social em cada esfera de ação, limitando os ideais normativos da eticidade democrática. Nesta seção, pretendo me deter de início a fazer uma rápida apresentação das três esferas sociais consideradas centrais por Honneth. Em seguida, passarei a analisar a importância de compreendermos a "correlação" dessas esferas, que forma a cultura política efetiva na qual se apoiam os ideais, valores e aspirações da eticidade democrática. Somente na última seção do artigo retomo os diagnósticos presentes no livro a respeito dos obstáculos à efetivação da liberdade e aproveito para tratar de alguns limites de sua formulação.

A "reconstrução normativa" de instituições e práticas que formam a eticidade

10 Estou parafraseando aqui a ideia de uma "teoria da justiça como análise da sociedade", que dá título à Introdução do livro. 
democrática é empreendida com a finalidade de mostrar que em cada esfera de ação central da sociedade democrática moderna se encontra enraizada uma normatividade social potencialmente imanente, a saber, o valor da "liberdade individual". ${ }^{11} \mathrm{E}$ em cada âmbito de ação, os sujeitos contraem cotidianamente vínculos intersubjetivos em comunidades particulares, nas quais se poderia verificar objetivamente a efetivação da liberdade mediante determinadas relações institucionalizadas de interação, reconhecimento e coordenação da ação no seio do mundo social. ${ }^{12}$ Considerada a partir de suas regras, normas e rotinas intrínsecas, cada esfera de ação concretiza de maneira diferenciada a normatividade social da liberdade individual intersubjetivamente constituída. Ou seja, embora as práticas sociais como um todo constituam sistemas de ação relacionais, as diferenciações de cada esfera podem ser coletivamente compartilhadas pelos indivíduos, pois os membros da sociedade "estão em condições de traçar linhas demarcatórias claras entre os diferentes sistemas de ação e realçar sua estrutura normativa uns em relação aos outros" (Honneth, 2011, p. 228). Partindo das diferenciações mais rotineiras da vida social moderna, Honneth identifica três sistemas de ação ou instituições relacionais: as esferas institucionais das relações pessoais, das ações nas economias de mercado e da esfera pública política.

As relações pessoais (compostas pelas relações de amizade, de intimidade e da família) formam o primeiro âmbito de ação social a ser considerado pela reconstrução normativa das práticas relacionais em que a liberdade individual se encontra institucionalizada. Elas são caracterizadas pelo desinteresse, compromisso pessoal e cuidado, sempre medidos, como no caso das outras esferas, pelas condições de reconhecimento recíproco e livre cooperação entre seus membros. Uma formação isenta de coerção e reflexiva na primeira esfera ajuda à disposição motivacional nas outras duas esferas, tanto na cooperação reflexiva do mercado quanto na participação política. A economia de mercado, por sua vez, também será considerada uma esfera da liberdade social. Neste caso, contudo, ampliam-se os modos de cooperação, antes circunscritos às relações pessoais, para a dimensão do consumo e do trabalho. Nessas duas primeiras esferas, Honneth considera

11 Honneth pretende assim com a reconstrução normativa "executar a reconstrução em toda a extensão do desenvolvimento atual de todas as esferas sociais de valor que sejam centrais. Com isso, trago para mim naturalmente o problema de ter de afirmar que essas diferentes esferas ou complexos de ação de fato representam corporificações de um valor prevalecente da liberdade individual" (Honneth, 2011, p. 120).

12 "A ideia hegeliana, segundo a qual a liberdade individual precisa ser 'objetiva', significa que são necessárias instituições apropriadas, ou seja, instituições de reconhecimento recíproco, para ajudar a dar efetividade de fato à liberdade reflexiva dos indivíduos" (Honneth, 2011, p. 123). É importante notar que são essas "instituições de reconhecimento recíproco" que poderão condensar normativamente os hábitos e costumes determinantes das práticas sociais. 0 conceito que Honneth tem de "instituição" é, por assim dizer, fraco, já que se refere à estabilização ou padronização de certos complexos de ação, hábitos, normas e regras compartilhados. Cf. Honneth (2011, p. 98-103). 
possibilidades de negociação e argumentação reflexiva entre os participantes como componente capaz de influenciar comunicativamente as condições de efetivação da liberdade social, as quais envolvem coparticipação em compromissos financeiros, estabelecimento de laços afetivos e sexuais, compartilhamento de tarefas domésticas e cuidado com filhos, viabilidade de projetos individuais e conjuntos etc., no caso da esfera pessoal; na esfera das relações de mercado, a institucionalização da liberdade comunicativa passa por alternativas de consumo sustentável e coletivização de formas produtivas, equilíbrio entre competição e cooperação, compromissos de inclusão, horizontalização e diversidade no ambiente de trabalho, negociação contratual e mediação de interesses, proteção social etc.

Por fim, a terceira e última dimensão da liberdade social é a da formação democrática da vontade. Nela se institucionalizam práticas políticas amplas, que envolvem tanto a possibilidade informal de formação da opinião em espaços associativos diversos (escolas, universidades, igrejas, bares, associações civis diversas) quanto a participação em organizações e instituições formais (partidos, Parlamento etc.). 0 princípio da inclusão igual de todos os cidadãos na esfera pública se efetiva mediante a qualidade desses espaços associativos, mas também pela mobilização cidadã (em manifestações, protestos e atos de desobediência civil), porosidade da tematização pública, acesso aos meios de comunicação, e a diversidade cultural e social de seus membros. Apenas assim, com a participação ilimitada e não coagida na formação política da vontade, a liberdade social se torna normativamente efetiva na vida pública democrática.

Ora, quando se trata de compreender o potencial normativo da eticidade democrática, a institucionalização de complexos de ação também precisa ser analisada para além dos padrões de diferenciação. Não se pretende com isso desdiferenciar os complexos institucionais de ação, os quais configuram papéis e funções normativamente relevantes para sociedades modernas marcadas pela diferenciação interna de padrões de ação relacionais. Trata-se antes de compreender que a eticidade democrática é constituída simultaneamente pela “correlação" entre cada uma das esferas diferenciadas de ação. Correlação significa que existe conexão e interdependência entre as formas de liberdade institucionalizadas. Esse é um argumento decisivo para a perspectiva de uma teoria crítica da democracia, porque evita que a normatividade social do ideal democrático fique circunscrita, por exemplo, tão somente à formação pública da vontade. Pelo contrário. A impossibilidade da liberdade na dimensão das relações íntimas ou do mercado coloca em xeque a própria democracia. Nesse sentido, em termos de cultura política, mesmo a liberdade política e a participação na esfera pública permanecem como que dependentes das condições de uma liberdade em certa medida já realizada nas 
outras esferas sociais. ${ }^{13}$ Honneth defende aqui a importante tese segundo a qual "as oportunidades de uma inclusão em pé de igualdade de cada membro da sociedade no processo democrático crescem na medida em que, nas esferas vizinhas das relações pessoais e do mercado econômico, são liberados e realizados a cada vez princípios institucionalizados da liberdade social” (Honneth, 2011, p. 614-615).

Portanto, a tese da correlação parece ser uma das mais importantes na sustentação de uma perspectiva crítica segundo a qual hábitos e comportamentos cotidianos que compõem nossas formas de vida influenciam a constituição da eticidade democrática:

A ideia da "eticidade democrática" tem em conta essa circunstância uma vez que, em última instância, considera só haver democracia onde os princípios da liberdade institucionalizados nas diferentes esferas de ação de fato são efetivados e se sedimentam nas práticas e costumes correspondentes; entre as respectivas esferas, portanto, há a mesma relação de reciprocidade contributiva que, no interior de cada esfera individual, existe entre as atividades especificadas segundo papéis dos indivíduos unidos em um "nós” (Honneth, 2011, p. 615).

Formulado positivamente, é como se na formação democrática da vontade se replicassem elementos centrais do reconhecimento recíproco e das condições da liberdade social gestados nas esferas "pré-políticas" das relações pessoais e do mercado. Pressupõe-se aqui que a normatividade social da democracia dependeria de processos de aprendizagem acumulados. Por essa razão, "o sistema social da eticidade democrática", continua Honneth, "apresenta uma rede complexa de dependências recíprocas, na qual a efetivação da liberdade específica em uma esfera de ação depende de que também nas outras esferas sejam realizados os princípios da liberdade subjacentes" (idem, p. 616). Esse sentido de correlação certamente retira a primazia da esfera pública política propriamente dita na justificação da legitimidade democrática em seu todo, já que esta deixa de ter sustentação normativa caso as liberdades individuais nas outras duas esferas não sejam socialmente efetivas: maustratos infantis, violência doméstica, assédio sexual, discriminação e exploração nas relações do mercado de trabalho são, por sua vez, alguns exemplos negativos dessa dependência recíproca e do modo como a falha (ou anomalia, como ainda veremos) nas condições relacionais para a efetivação da liberdade social nas primeiras duas esferas poderia minar as condições gerais da democracia.

Mas se a formação democrática da vontade pressupõe certas condições de liberdade efetivadas de algum modo nas outras esferas, também essa terceira instituição relacional é promotora da liberdade em um movimento que vai da esfera

13 "A relação entre as esferas é muito mais complicada, pois a efetivação da liberdade social na esfera pública democrática está ligada por sua vez ao pressuposto de que os próprios princípios da liberdade social estejam parcialmente realizados nas esferas das relações pessoais e da economia de mercado" (Honneth, 2011, p. 473). 
pública para a dimensão do mercado e das relações íntimas. ${ }^{14} \mathrm{Na}$ verdade, "a esfera da formação pública da vontade possui [...] uma posição superior” (Honneth, 2011, p. 616) em relação às outras duas esferas. Segundo Honneth, isso ocorre porque se trata de uma dimensão constituída essencialmente pela "autotematização reflexiva", o que a diferencia das outras: "somente na esfera democrático-política a cooperação dos sujeitos é pensada como uma troca recíproca de argumentos, ou seja, um processo reflexivo" (idem, p. 617). Assim, a formação pública da vontade, ao estabelecer de maneira mais característica o debate reflexivo de temas sociais e políticos diversos, pode também contribuir decisivamente para a efetivação da liberdade nas outras duas esferas, isto é, para a "democratização da família ou da economia": "O processo democrático, por sua vez, está agora sob certa carência normativa, pelo fato de só se ajustar à sua própria pretensão de liberdade se também encorajar e fortalecer simultaneamente as aspirações à liberdade nas outras duas esferas de ação" (idem, p. 618). Honneth se refere, por exemplo, às lutas feministas na arena política e ao modo como suas pautas públicas puderam levar a conquistas sociais e legais no âmbito das relações familiares e do mercado de trabalho - e estas conquistas apontam, de maneira interdependente, ao êxito das pretensões que o próprio movimento feminista ergue na esfera pública.

Em seu livro seguinte, $A$ ideia de socialismo, Honneth explicita ainda mais o vínculo entre sua compreensão da democracia como forma de vida e a correlação das esferas sociais. Uma vez que procura libertar a "ideia do socialismo" da interpretação economicista e mostrar o nexo estreito entre democracia radical e o ideal socialista, ou seja, a necessidade de incluir na reflexão socialista uma preocupação a respeito das condições de efetivação da liberdade social em toda sua extensão, Honneth ressalta a correlação da dimensão econômica com as relações íntimas e com a formação pública da vontade. Também aqui as três esferas sociais de efetivação da liberdade devem estar atreladas entre si para que assim se constitua em sua essência uma sociedade democrática diferenciada: "A imagem retida de uma tal correlação [...] das esferas de liberdade independentes pode ser descrita como a súmula da representação de uma forma de vida democrática" (Honneth, 2015, p. 144). Certamente, também nesta formulação, "democracia" não significa apenas poder participar em pé de igualdade e sem constrangimentos nos procedimentos de formação política da vontade. Entendida como forma de vida, ela aponta para a experiência da participação igualitária no conjunto da sociedade. Por esta razão, conclui Honneth,

A nossa sociedade só se tornaria social no pleno sentido da palavra se todos os seus

14 Pois "seus participantes aprendem que as lutas sociais pela reivindicação da liberdade institucionalizada a cada vez nas outras esferas de ação recebem apoio porque representam assim as condições de sua própria liberdade" (Honneth, 2011, p. 615-616). 
membros pudessem satisfazer as necessidades partilhadas de intimidade física e emocional, de independência econômica e de autodeterminação política com todos os outros de tal modo que pudessem contar com a participação e a ajuda de seus parceiros de interação (idem, p. 166).

Assim, a primeira ideia fundamental apresentada por Honneth consiste em mostrar a importância da correlação entre as esferas para a constituição de nossa cultura política. 0 projeto de uma sociedade democrática não se sustenta apenas quando nos limitamos a investigá-la como forma de governo ou quando asseguramos legalmente a liberdade política dos cidadãos. Opressões e violações que impossibilitam a autodeterminação e a autorrealização de cada indivíduo, atentando socialmente contra a liberdade em sentido amplo e diferenciado, também ameaçam essencialmente a democracia. Não há dúvidas de que violações sistemáticas contra a autonomia das pessoas revelam, junto à percepção negativa que trazem para os próprios concernidos, que a liberdade é uma medida socialmente vigente, ainda que não plenamente realizada em todas as dimensões da vida. ${ }^{15}$ Tais violações, vividas nas mais diversas esferas de interação da sociedade, lançam luz às pretensões normativas imanentes às práticas sociais enquanto tais, levando a consequências importantes para a qualidade de nossa vida democrática. Já que o processo democrático, segundo a exposição honnethiana, intersecciona-se com as aspirações à liberdade em outras esferas de ação. Podemos ver então que há um entrelaçamento entre tais âmbitos na medida em que a própria disputa na esfera pública (por direitos, por participação política etc.) avançaria em termos emancipatórios junto à efetivação cada vez maior da liberdade em outros domínios das interações sociais. Sua outra ideia central consiste em mostrar a importância da relação entre a dimensão pública da autodeterminação política, já enfatizada, como vimos, por outras teorias radicais da democracia, e o efeito democratizador que poderia produzir sobre as outras esferas sociais.

III

Um dos propósitos do presente artigo consistiu em mostrar que Honneth pode contribuir com a formulação de uma teoria crítica da democracia. Como vimos, ele questiona o ideal democrático mediante uma democratização, por assim dizer, de práticas sociais comumente consideradas “pré-políticas”. Ao se voltar às esferas da eticidade moderna, a perspectiva de análise abriu caminho para uma reflexão crítica sobre os desafios da democracia que estivesse fundamentada de maneira imanente nas práticas sociais enquanto tais. Por este motivo, Honneth contribui ao ampliar a análise da teoria democrática para além das dimensões jurídico-políticas, uma vez que seu empreendimento de uma reconstrução normativa dos ideais da justiça e da

15 Tema que será explicitado em Honneth (2020). 
democracia pressupõe que toda a normatividade seja socialmente produzida. $^{16}$

No entanto, não apenas os domínios de efetivação da liberdade, mas também seus desvios e "desenvolvimentos anômalos" [Fehlentwicklungen] fizeram parte do propósito crítico do texto de Honneth. Uma anomalia social é diagnosticada quando não é possível efetivar a liberdade social subjacente a uma das esferas sociais: o padrão intrínseco de ação social fracassa por violar suas regras constitutivas. E isso significa que a liberdade individual, que deveria ser satisfeita pelas instituições diferenciadas de reconhecimento recíproco, deixa de contar com as condições sociais de comprometimento adequadas. As anomalias, que atingem os comportamentos dos sujeitos em cada esfera e impedem a efetivação da liberdade social, podem ser verificadas como decorrência de dois processos: ou as regras, normas e rotinas que regulam normativamente cada complexo de ação são “invadidas” pelos critérios que são intrínsecos a outras esferas de ação, desbotando as linhas demarcatórias que determinam normativamente o exercício intersubjetivo, racional e reflexivo da liberdade institucionalizada; ou as práticas sociais de cada uma das três esferas simplesmente se submetem aos imperativos econômicos de valorização do capital. Nesse sentido, sempre devemos compreender os desenvolvimentos anômalos como desvios nas próprias regras constitutivas dos sistemas de ação (Honneth, 2011, p. 230231). Ambos os casos levam a uma “desdiferenciação” indesejável entre as esferas, o que modifica de maneira heterônoma as práticas e costumes intersubjetivamente compartilhados em cada complexo de ação e, assim, expõe uma espécie de desvio na normatividade social originalmente inscrita na eticidade democrática.

Ora, deste modo, as anomalias sociais, ainda que expusessem os problemas das interações em cada esfera institucionalizada, foram compreendidas antes de tudo como desequilíbrios funcionais na reprodução social. ${ }^{17}$ Pouca atenção foi dada a outras causas de violação sistemática da liberdade, às experiências cotidianas que, por motivos e constrições variados (racismo, sexismo, por exemplo), impossibilitam a autorrealização cooperativa dos indivíduos. Essa negligência coloca limites à teoria crítica de Honneth para diagnosticar e compreender os conflitos sociais contemporâneos e, por conseguinte, os sentidos da democracia. Pois entendemos que as experiências sociais negativas (tais como aquelas produzidas pelo desrespeito, exploração, discriminação e violência) aprofundam os diagnósticos sobre as violações da liberdade e sobre as ameaças existentes às formas de vida democráticas. Mas

$16 \mathrm{Na}$ trilha da reconstrução normativa da liberdade social, e direcionado contra as teses centrais de Facticidade e validade, de Habermas, Honneth afirma que "as categorias do direito não são mais suficientes para apreender as bases especificas de validade e as figuras sociais presentes a cada vez. Muito do que, nas estruturas de sustentação, encontra-se sobretudo nas esferas da liberdade social, possui mais o caráter de práticas, costumes e papéis sociais do que de facticidades jurídicas" (Honneth, 2011, p. 125).

17 Sobre a incorporação do argumento funcionalista nessa formulação de Honneth, cf. anteriormente a nota 6. 
não apenas isso. Tais experiências permitem entender que o diagnóstico dos riscos à democracia passa pelas "lutas sociais" desencadeadas em nossas sociedades. Somente assim a normatividade não permaneceria despolitizada.

Uma fenomenologia das opressões cotidianas e a respectiva preocupação com o modo como a socialização é permeada por conflitos e lutas sociais por reconhecimento é algo que podemos depreender de uma leitura imanente às pretensões do próprio Honneth. Em alguns trabalhos anteriores é possível destacar formas mais complexas de compreender, à luz das próprias interações cotidianas, fenômenos negativos de subjetivação. Sabe-se que uma das teses centrais do seu mais conhecido livro, Luta por reconhecimento, consistiu em mostrar o vínculo entre experiências morais cotidianas de desrespeito e a gramática moral das lutas sociais (Honneth, 2003). No escopo deste livro, Honneth dá especial atenção à injustiça vivida pelos indivíduos em formas variadas de desrespeito e denegação do reconhecimento, passando por violações pessoais, privação de direitos e degradação social. E no contexto de outro estudo de teoria do reconhecimento, Honneth atualiza o conceito de "reificação" como expressão de anomalias presentes em práticas sociais e atitudes cotidianas que constituem nossa forma de vida (Honneth, 2018, p. 29). Neste último caso, trata-se de conceber fenômenos sociais de "desumanização" (naturalizados por ideologias e estereótipos) de indivíduos e grupos, como poderia ocorrer, por exemplo, em casos de opressão e subjetivação causadas estruturalmente por racismo e sexismo. ${ }^{18}$

Contudo, na exposição de $O$ direito da liberdade, a preocupação funcionalista acaba se sobrepondo à fenomenologia das relações de dominação em cada esfera social. Vejamos o caso das relações de intimidade. Como afirma Felipe G. Silva,

embora Honneth ressalte a importância de se refletir sobre as particularidades da esfera íntima no interior do pensamento democrático, seus desenvolvimentos [...] encontram-se longe de encerrar o assunto. [...] Com efeito, Honneth não parece ter superado o silenciamento que a categoria da privacidade impunha às injustiças cometidas no âmbito da vida íntima. A intimidade continua sendo apresentada como uma esfera de liberdade quase que absoluta - e se não o é completamente, isso se deve a "influências" e "penetrações" da lógica de esferas sociais alheias, mas não a patologias que se reproduzem ali internamente. Ao que parece, seu próprio programa reconstrutivo parece impedi-lo aqui de desenvolver um diagnóstico mais robusto sobre os bloqueios à democratização interna da esfera íntima (Silva, 2013, p. 216).

O maior problema consiste em não diagnosticar experiências cotidianas de opressão

18 Com isso, entendo que essas práticas sociais reificadoras, abordadas de maneira abstrata por Honneth, podem e precisam ser articuladas com experiências concretas. Algo muito semelhante preocupa, por exemplo, os estudos interseccionais de A. Brittan e M. Maynard: “A dominação sempre envolve a objetificação do dominado; todas as formas de opressão implicam a desvalorização da subjetividade do oprimido" (1984, p. 199). Remeto também às formas de dominação como processos objetivadores de desumanização tratadas por P. Hill Collins: "Tanto ideologias racistas como sexistas compartilham a característica comum de tratar grupos dominados - os 'outros' como objetos aos quais faltam plena subjetividade humana" (2016, p. 106). 
que fazem parte da esfera social composta pela família e pelas relações íntimas, o que levaria a uma espécie de neutralização da dimensão do poder vinculada a esse domínio da liberdade social. ${ }^{19}$

A mesma coisa ocorre em relação à importância da luta social para a constituição da eticidade democrática e da cultura política. O próprio Honneth afirma que as "lutas sociais" são responsáveis por configurar e efetivar as condições de realização da liberdade social institucionalmente diferenciadas, e isso em todas as esferas sociais de ação, não somente quando ocorrem na esfera pública: "O motor e o meio dos processos históricos de realização dos princípios institucionalizados da liberdade não é, em primeira linha, o direito, mas são as lutas sociais por sua compreensão adequada e as mudanças de comportamento daí resultantes" (Honneth, 2011, p. 631-614). Entretanto, não resta dúvidas de que, em comparação com Luta por reconhecimento, a reconstrução normativa das esferas sociais e das instituições relacionais operada em $O$ direito da liberdade representa um distanciamento de Honneth em relação ao "paradigma da luta" na fundamentação mais recente de sua teoria crítica. ${ }^{20}$

A recuperação da centralidade das lutas sociais é crucial para a tese geral da democratização das formas de vida, já que passam por dimensões cotidianas de experiências e de conflitos gerados em espaços sociais diversos. No quadro plural da teria crítica, é o que temos aprendido especialmente com um tipo de abordagem

19 Em outra passagem, o autor explicita essa neutralização imanente do poder no interior da esfera íntima: "Honneth descreve o desenvolvimento moderno da esfera íntima como um processo de autonomização que conduz unilateralmente a avanços democratizantes. Ao supor que os riscos atuais à efetivação da liberdade encontram-se basicamente em sua invasão pela lógica de esferas sociais alheias, Honneth assume um vínculo tão direto entre diferenciação social e liberdade individual que the escapam quaisquer constrições à liberdade produzidas de modo endógeno. Isso se reflete [...] no modo como o autor neutraliza o universo íntimo de toda experiência de poder ali encontrada [...] Dessa maneira, a normatividade social que perpassa a intimidade nos é apresentada como se destituída de qualquer experiência de poder significativa. Nada em seu interior coage à assimilação de papéis, à normalização de condutas e à restrição de competências; em uma eticidade democrática, os indivíduos parecem decidir livremente sobre o formato de seus relacionamentos pessoais sem quaisquer pressões de adaptação" (Silva, 2013, p. 222).

20 Sobre o problema mencionado do distanciamento do "paradigma da luta", cf. Melo (2014, 2018). Com este mesmo propósito, Mariana Teixeira comenta: "É como se Honneth abdicasse de reconstruir a gramática profunda das lutas sociais por reconhecimento e passasse a centrar esforços em reconstruir a história institucional na qual se cristalizam as concepções modernas de liberdade [...] Esse foco na reprodução social e não na autorrealização individual explica a abordagem limitada e assistemática das experiências negativas dos atores sociais em $O$ direito da liberdade. Apesar de certamente presentes no livro, os obstáculos à emancipação (entendida como autorrealização) aparecem, no entanto, não como fontes normativas para a luta social e as transformações históricas, mas antes como desenvolvimentos sociais anômalos, isto é, como desvios de uma realização progressiva, não necessariamente conflituosa da liberdade individual [...] Dito de outro modo: a negatividade perde seu potencial histórica e potencialmente produtivo, e passa a ser vista como uma interrupção anômala que apenas pode levar o desenvolvimento histórico-social a um estado de estagnação ou mesmo regressão, e não a um processo conflituoso e doloroso de aprendizado social" (Teixeira, 2016, p. 360). Para uma abordagem posterior a $O$ direito da liberdade sobre a atualidade das lutas sociais por reconhecimento, cf. Honneth (2014). 
muito presente na literatura do feminismo negro. A despeito de suas diferenças, Angela Davis (2016), Patricia Hill Collins (2019) e Grada Kilomba (2019) nos mostram, para ficar com três importantes exemplos, a vinculação estreita entre experiências de opressão compartilhadas por afro-americanas em diferentes lugares e momentos, que atingem as mulheres negras nas relações familiares, nos trabalhos domésticos, nas relações de gênero e de classe, nas experiências associativas, na exclusão e desvalorização da esfera pública, em suas relações afetivas, trabalhistas e políticas. Mas não apenas isso. Elas destacam ainda a importância de compreender que, apesar da complexidade e da violência das experiências sociais compartilhadas, há ao mesmo tempo um processo de reelaboração dessas mesmas experiências na construção do ativismo dessas mulheres na luta contra o racismo, o sexismo e opressões de classe. ${ }^{21}$ Ou seja, tais autoras se preocupam em ampliar a noção de "ativismo", incorporando aspirações emancipatórias às lutas pontuais e tomadas de consciência cotidianas que acompanham as formas de vida das mulheres negras. Caso contrário, seria impensável tornar efetiva a democracia com um tal grau de injustiça social permeando todas as dimensões da sociedade (pois, na experiência das mulheres negras, a opressão atravessa sistematicamente as mais diferentes dimensões da vida social, seja na família e nas relações pessoais, no trabalho ou na política).

Se a teoria crítica se coloca a tarefa de refletir sobre as formas de vida democráticas, alterando a perspectiva mais tradicional na qual a democracia é investigada como uma forma político-jurídica de governo, então é fundamental se aproximar das experiências cotidianas de desrespeito e opressão que estruturam relações injustas de poder. Pois enquanto existir racismo, sexismo, homofobia, desigualdades sociais e exploração de classe, permanece ameaçada a forma de vida democrática. E em termos emancipatórios, não bastam respostas políticoinstitucionais. Temos de lutar para que a dignidade dos seres humanos e o respeito pela liberdade de cada um seja socialmente inerente às atitudes e modos de ação em todas as dimensões de nossa forma de vida. Por esta razão, uma teoria crítica da democracia precisa atentar - na esteira das demandas já existentes dos movimentos sociais - para a democratização em sentido amplo, isto é, para uma reflexão sobre a política que não desconsidere o modo como o poder se organiza e funciona nas diferentes esferas das sociedades modernas (capitalistas e democráticas), que compreenda como os indivíduos e grupos subordinados convivem com os efeitos da dominação na vida cotidiana, e leve em consideração que a gênese da resistência e

21 "Como de geração em geração as afro-americanas permanecem relegadas à base da hierarquia social, elas têm claro interesse em fazer oposição à opressão. Para a maioria das afro-americanas, essa não é uma questão intelectual - é uma realidade vivida. Enquanto as mulheres negras forem oprimidas, persistirá também a necessidade de seu ativismo [...] Opressão e resistência permanecem intrinsecamente ligadas, de tal maneira que a forma de uma afeta a da outra" (Collins, 2019, p. 434-435). No mesmo sentido: “Onde há opressão, há resistência. Em outras palavras, a opressão forma as condições de resistência” (Kilomba, 2019, p. 69). 
da luta se encontra localizada no seio da opressão social. Em toda sua ambiguidade e complexidade, nossa cultura política democrática condensa simultaneamente o bloqueio e a promessa, a opressão e a luta, o poder e a justiça em cada expressão histórica e social de suas formas de vida.

\section{Referências}

Brittain, A. e Maynard, M. (1984). Sexism, Racism, and Oppression. New York: Blackwell.

Collins, P. H. (2016). Aprendendo com a outsider within: A significação sociológica do pensamento feminista negro. Revista Sociedade e Estado, 31(1), 99-127. DOI: https: //doi.org/10.1590/S0102-69922016000100006

Collins, P. H. (2019). Pensamento feminista negro. São Paulo: Boitempo.

Davis, A. (2016). Mulheres, raça e classe. São Paulo: Boitempo.

Deranty, J- P. (2018). A teoria crítica entre Marx e Honneth. Civitas, 18(3), 630-653. DOI: https: //doi.org/10.15448/1984-7289.2018.3.32249

Dewey, J. (1954). The Public and its Problems. Chicago: The University of Chicago Press.

Forst, R. (2010). Contextos da justiça. São Paulo: Boitempo.

Habermas, J. (2018). “Três modelos normativos de democracia”. In: Habermas, J. A inclusão do outro. São Paulo: UNESP.

Habermas, J. (2020). Facticidade e validade. São Paulo: UNESP.

Honneth, A. (1986). Kritik der Macht. Frankfurt am Main: Suhrkamp.

Honneth, A. (2000a). "Pathologien des Sozialen: Tradition und Aktualität der Sozialphilosophie”. In: Honneth, A. Das Andere der Gerechtigkeit. Frankfurt am Main: Suhrkamp.

Honneth, A. (2000b). "Demokratie als reflexive Kooperation: John Dewey und die Demokratietheorie der Gegenwart". In: Honneth, A. Das Andere der Gerechtigkeit. Frankfurt am Main: Suhrkamp.

Honneth, A. (2003). Luta por reconhecimento: A gramática modal dos conflitos sociais. São Paulo: Ed. 34.

Honneth, A. (2007). Sofrimento de indeterminação: Uma reatualização da filosofia do direito de Hegel. São Paulo: Esfera Pública.

Honneth, A. (2011). Das Recht der Freiheit. Berlim: Suhrkamp.

Honneth, A. (2014). Barbarizações do conflito social. Civitas, 14(1), 154-176. DOI: https: //doi.org/10.15448/1984-7289.2014.1.16941

Honneth, A. (2015). Die Idee des Sozialismus. Berlim: Suhrkamp.

Honneth, A. (2018). Reificação: Um estudo de teoria do reconhecimento. São Paulo: UNESP.

Honneth, A. (2020). Die Armut unserer Freiheit. Frankfurt am Main: Suhrkamp.

Jaeggi, R. (2014). Kritik von Lebensformen. Berlin: Suhrkamp. 
Kilomba, G. (2019). Memórias da plantação: Episódios de racismo cotidiano. Rio de Janeiro: Cobogó.

Melo, R. (2014). Da teoria à práxis? Axel Honneth e as lutas por reconhecimento na teoria política contemporânea. Revista brasileira de ciência política, 15, 17-36. DOI: https: //doi.org/10.1590/0103-335220141502

Melo, R. (2017a). A soberania popular revisitada: Autogoverno como modo de vida. Cadernos de Filosofia Alemã: Crítica e Modernidade. 22(3), 57-68. DOI: https: // doi.org/10.11606/issn.2318-9800.v22i3p57-68

Melo, R. (2017b). “Esfera pública e cultura política: Hipóteses de investigação sobre as novas mobilizações sociais no Brasil”. In: Werle, D. L. et. al. (orgs.). Justiça, teoria crítica e democracia. Florianópolis: Nefipo Online.

Melo, R. (2018). Dimensões políticas do reconhecimento e seus limites. Dissonância, 2, 112-148.

Nobre, M. (2013). "Reconstrução em dois níveis: Um aspecto do modelo crítico de Axel Honneth”. In: Melo, R. (org.). A teoria crítica de Axel Honneth: Reconhecimento, liberdade e justiça.

Pinsdorf, C. (2016). Lebensformen und Anerkennungsverhältnisse. Berlin: Walter de Gruyter.

Silva, F. G. (2013). "Um ponto cego no pensamento político? Teoria crítica e a democratização da intimidade". In: Melo, R. (org.). A teoria crítica de Axel Honneth: Reconhecimento, liberdade e justiça.

Teixeira, M. O. N. (2016). Patologias sociais, sofrimento e resistência: Reconstrução da negatividade latente na teoria crítica de Axel Honneth. Tese de doutorado. Unicamp.

Wellmer, A. (1993). "Bedingungen einer demokratischer Kultur. Zur Debatte zwischen ‘Liberalen’ und ‘Kommunitaristen’”. In: Wellmer, A. Endspiele: Die unversöhnliche Moderne. Frankfurt am Main: Suhrkamp. 